\title{
Uncovering the Sociopolitical Situatedness of Accents in English in the World Englishes paradigm
}

Reference: Luk, J. \& Lin, A. (2006). Uncovering the sociopolitical situatedness of accents in World Englishes paradigm. In Hughes, R. (Ed.) Spoken English, applied linguistics and TESOL:Challenges for theory and practice (pp. 3-22). Basingstoke: Palgrave.

\begin{abstract}
Despite a call for liberal acceptance of multiple standards of spoken English in some recent World Englishes discussions, English spoken with a non-native accent continues to be stigmatized, and attempts to eliminate one's native accent for social and professional advancements have continued to shape and constitute the ESL/EFL speaker's ethnic and sociocultural identities and subjectivities. Through a critical analysis of the research literature, and reflexive analysis of lived experiences of ESL/EFL speakers, the authors in this paper will explore how Anglo- and US-centric pronunciation norms continue to be privileged through institutional apparatuses such as media and education in post-colonial Hong Kong. The authors call for an ideological critique of the naturalization of Anglo-centric accents and a critical examination of the role played by ESL/EFL speaker accents on the life trajectories and sociocultural positioning of second and foreign English speakers through high-stake assessment mechanisms. The research task is thus both sociopolitical and applied linguistic theoretical: (1) sociopolitically how to create alternative discourses, re-imaginations and visions about what count as prestigious accents, (2) applied linguistic theoretically, how to develop research and pedgagogic paradigms that seek to enhance mutual intelligibility by "reverse" applied linguistic research and education: research on and development of applied linguistic programmess in educating the Anglo- or ethno-centric ear in the world's diverse accents.
\end{abstract}

\section{Introduction - Englishes in a world tug-of-war}

The emergence of the "World Englishes" paradigm over the last two decades has boosted the morale and confidence of many ESL/EFL users in the outer and expanding circles ${ }^{\mathrm{i}}$ (Kachru, 1992). Sobering and thought-provoking questions such as "Who owns English? Who are the native speakers of English? Is there "Standard English"? Whose standards?" proffered by Inner Circle experts (e.g. Pennycook, 1994; Phillipson, 1992; Widdowson, 1993) challenge the hegemonic status of BANA-centric (British-Australasia-North American model, in Holliday's (1994, p.12) term) norms and capture the hearts of many souls in the former colonies of Britain and America. The paradigm shift seems to have resulted in a more liberal attitude towards local varieties of English. Local usage not conforming to the British and American norms may not be regarded as errors as long as it is commonly adopted by the local community. As argued by Smith (1983, p.39), who is one of the early advocates of world Englishes, "non-mother-tongue user does not need to become more like Americans, the British, the Australians, the Canadians or any other English speaker in order to lay claim on the language." As its logo-acronym "WE" 
suggests, there seems "a club of equals" (McArthur, 1993, p.334) with English users from across the world enjoying equal status and authority to contribute to the setting of standards. For a time, the WE paradigm boosts ESL/EFL users' confidence and heightens their awareness of their language rights. For example, Baxter (1991) boldly argues for the legitimate rights for Japanese to speak English in a manner appropriate to the local community because speaking English Japanesely "does not threaten the speaker nor come into conflict with this person's identity" (p.65).

At a more practical applied linguistic level, there were various attempts to establish an international variety of English (EIL) (e.g. Modiano, 1999) or a World Standard English (e.g. McArthur, 1987; Crystal, 2003) which English users engaging in international communication should employ to facilitate mutual intelligibility. It is believed that this international variety of English could even supersede the British and American varieties (see Jenkins, 2003 for a comprehensive review). In this sense, the paradigm seems to be moving from "World Englishes" to an internationally accepted "World English" (Brutt-Griffler, 2002). Jenkins' (2000, 2002) work on establishing a Lingua Franca Core (LFC) of English phonology for international communication is a representative and concrete endeavour to bring about a common understanding among world English users of what segmental and suprasegmental components ESL/EFL students and teachers should aim to master for mutual intelligibility in realistic interethnic communications. Her work was based on empirical and contrived studies which draw on data from natural interactions between EIL (English as an International Language) users from Japan, Taiwan, and Korea. Jenkin's (2000) work enhances mother-tongue and non-mother-tongue English users' awareness of pronunciation variants across varieties due largely to the inherent differences and practices of speech across different national phonological systems. Apart from adopting a teachability-learnability criterion, Jenkins (2000) selects phonological features to be included in LFC core on two considerations: (1) whether the phonological features have shown to be hampering speech intelligibility in real interethnic communications from empirical data; and (2) whether the phonological features are commonly realized in most of the major phonological systems of world languages. For example, the voiced interdental fricative 'th' sound as in 'there' was found to be commonly substituted with the dental variant [d] by many L1 and L2 English users; or the dark [1] was found to be becoming vocalic in most other varieties of English and therefore it was quite unproblematic for words such as 'bill' to be pronounced as /bIY/ . The voiced interdental fricative 'th' and the dark /1/ are thus not to be included in the LFC core.

Jenkin's (2000) work seems to have pointed to a clear direction forward for a common understanding to be achieved about what a World variety of English used by people across all nations would be like. However, the everyday scenario may not really be that orderly and optimistic. As pointed out by Jenkins (2000), speakers substituting /t/ and /d/ for $/ \mathrm{T} /$ and $/ \Delta /$ respectively would still be stigmatized in the English L1 communities by speakers of RP, GA, and other more standard L1 varieties. Brutt-Griffler (2002) also 
points out the resiliency of the tacitly assumed standpoint that the "ownership of English" still rests with mother tongue users of English.

The founding theorist of "linguistic imperialism", Robert Phillipson, has on more than one occasion warned that ideology revealing "linguistic ethnocentricity" and "linguicism" largely goes unchallenged. He observes that there were still "inequalities and a-symmetry in 'international communication' [which] places non-native users of English lower on a hierarchy of norms of communication than native English-speakers", and there were still tendencies to view "Other" cultures and languages as "deficits" (Phillipson, 2000, p.275). So, what matters more seems not to be "who owns English", but who owns the authority and control over value judgment of different norms of usage of English varieties. English as a commodity comes in many brands. Owning only the low-end English (i.e. English spoken with distinct non-standard characteristics) may not yield too much benefit to its owner. Brutt-Griffler (2002) mentions attempts to view the use of English as an international language $(E I L)$ as reflecting features of an "interlanguage" (IL) (Selinker, 1992) from a second language learning (SLA) perspective. Though these attempts have not been successful, they imply that users of English as an international language may be viewed by some mainstream second language educators as simply having deficient English proficiency.

Very recently, Pennycook (2003) criticizes the large body of work on World Englishes as representing only circular arguments because "the WE paradigm focuses only on standardized norms of English in limited domains" (p.517). Uncodified varieties in the expanding circle still hold the status of errors. It seems clear that hegemony continues to exist in the World English paradigm which is "far too exclusionary to be able to account for many uses of English around the world" (p.521). He shows support to Parakrama's (1995, p.17) view that the WE paradigm "cannot do justice to those Other Englishes as long as they remain within the over-arching structures that these Englishes bring to crisis. To take these new/Other Englishes seriously would require a fundamental revaluation of linguistic paradigms, and not merely a slight accommodation or adjustment." Pennycook (2003) calls for actions to break away from the exclusionary constrictive circles which only incorporate codified national varieties and take seriously varieties arising from globalization, popular culture and Other Englishes.

The crux of the issue, perhaps, is how the new/Other Englishes should be taken seriously, by whom, and who would benefit from such an outcome. The present paper attempts to contribute to the discussion by revealing how English linguistic hegemony continues, perhaps with increased strength, to manifest itself through various social and political institutional apparatuses in the latest member of the post-colonial club, Hong Kong, with particular reference to accents and speaking proficiency. Through a critical analysis of the research literature, evidence from public discourses, and reflexive analysis of lived experiences of ESL/EFL speakers including the authors themselves, we will investigate how local people might have actually suffered, instead of benefited, from the WE 
paradigm. We will explore two forces at work that are pulling at different ends, one representing an applied linguistic theoretical view focusing on mutual intelligibility, and one representing an underlying sociopolitical ideology focusing on social stigmatization of accents in pronunciation. We will discuss how and why it would be difficult and may not be desirable to achieve "a fundamental revaluation of linguistic paradigm" as advocated by Pennycook in places such as Hong Kong.

\section{Accent and World Englishes}

We have chosen World Englishes accent to be our focus of analysis because of the intricate role speech accents play as a sociolinguistic phenomenon as well as, if not more than, a linguistic phenomenon. Accents are defined by Lippi-Green (1997) as "loose bundles of prosodic and segmental features distributed over geographic and/or social space." Accent is more than anything else a powerful linguistic marker of age generations, social identity, social class, education level, and ethnicity. The accent used by the flower girl in George Bernard Shaw's "Pygmalion/My Fair Lady" immediately marked her off as belonging to a lower socio-economic class and a poor region.

Stories about how L2 English users and their accented speech were negatively discriminated against in contexts ranging from the classroom to the workplace have been well-documented (e.g. Eisentstein, 1983; Canagarajah, 1999; Lippi-Green, 1997). There were regular advertisements publicizing "accent elimination" services and news broadcasting successful efforts. Accent discrimination does not only happen to non-mother-tongue English speakers. As pointed out by Jenkins (2000), many teachers considered (which was felt to be wrong by Jenkins) Standard English to mean English spoken with a prestigious accent, RP, or a modified form of it. This implies that English spoken with non-RP accent will be perceived as sub-standard. Subjective and emotional adjectives such as "stupid" were sometimes used to refer to regional accents. This negative mentality towards accents was also reflected in an early definition of the term "accent" in a prestigious dictionary with a heavy judgmental tone by including "mispronunciation of vowels or consonants, misplacing of stress, and misinflection of a sentence" (Oxford English Dictionary, 1989, quoted in Lippi-Green, 1997, p.58) as features of accents. The authors of this paper checked the 2003 version of Cambridge Advanced Learners' Dictionary and found a much more neutral definition -- "the way in which people in a particular area, country or social group pronounce words." However, one of the examples given ("She's French but she speaks with an impeccable English accent") still carries the myth behind accent and proficiency. First, there is an "impeccable" English accent. Second, it is beyond most people's expectation that a non-native English speaker could speak with that impeccable English accent. Even recently, there were findings showing a general tendency to connect accent with teaching competence. Foreign teaching assistants speaking English with an accent perceived to be intelligible by the students were considered to have higher teaching competence than those who speak with a less intelligible accent (Bresnahan, Ohashi, Nebashi, Liu and 
Shearman, 2002).

Over the last two decades, there were clear efforts to raise English users' awareness of the inequalities arising from such language ideology and attempts to counteract language subordination were proposed. Lippi-Green (1997) argues forcefully that language subordination based on accent discrimination is not about "relative standards", but about "taking away a basic human right: to speak freely in the mother tongue without intimidation, without standing in the shadow of other languages and peoples" (p.243). To resist the process of language subordination, according to Lippi-Green, is to ask for "recognition, and acknowledgement" of such linguistic human rights. However, the authors of this paper would like to point out that to obtain recognition and acknowledgement of such human rights is one issue, to evaluate the gains and losses of social and cultural capital in highly sociopolitical situations arising from an overt display of such human rights is perhaps another.

\section{Positioning post-colonial Hong Kong in the WE paradigm: Speculations and realities}

In the last few years running up to the handover of sovereignty from Britain to China on 1 July 1997, speculations about the language profile of the Hong Kong society permeated the public and academic discourses. Views were of course diverse but one representative view tended to envisage a declining importance of English in Hong Kong. For example, in his paper discussing societal accommodation to English and Putonghua in Hong Kong at the $20^{\text {th }}$ Century's end, Pierson (1998) quotes several references (e.g. Godfrey, 1992; Harris, 1989; Lau, 1991; Purves, 1989; Surry, 1994) published a few years earlier predicting decreasing value of English as one of Hong Kong's greatest asset. It was reported that demand for English instruction had already experienced a noticeable slump leading to the closing down of some commercially operated English tuition centers (Godfrey, 1992). It was even suggested by Surry (1994) that the ability to use English well is no longer of much concern to the business community. Lau (1991) speculated that Putonghua would replace English as the "language of success".

These views that forecasted a decline in the status of English in preference for the national language of China, Putonghua, though speculative in nature, were by no means groundless as precedents could easily be found in other former colonies of Britain. In speculating the future of English as a global language, Crystal (2003) points out a common dilemma in several colonies-turned independent states such as Africa, India, the Phillipines, Pakistan, and Singapore that post-colonial subjects often display "a strong reaction against continuity to use the language of the former colonial power, and in favour of promoting the indigenous languages" (Crystal, 2003, p.124). However, Crystal (2003) was quick to add that it does not mean that these nations had totally rejected English. To fulfill the need to assert their national identity while making sure not to be left out from important world affairs, most of these post-colonial people continue to learn to master 
English, but tend to prefer using English in their "own way" or a hybridized form of speech constituting several linguistic codes (Canagarajah, 2000). As suggested before, the feeling of identity and group solidarity has been found to be most palpable in the choice of accents in speaking the language of the former colonial masters. Kachru (1986), for example, reports findings from a number of studies conducted in former colonies of Britain and America such as India, Singapore, Malaysia, Puerto Rico, the Phillipines, Nigeria, and Sri Lanka showing an almost unanimous attitude of the post-colonial subjects to demonstrate their preference for the localized varieties and an overt unfavourable attitude towards accents bearing traits of the colonizers' speech.

As a new member of the post-colonial club, Hong Kong, however, does not seem to have displayed similar attitudes as described above. In Kachru's (1992) concentric-circle model of World Englishes, India, Kenya, Pakistan, Sri Lanka, Phillippines, and Singapore were all situated in the "Outer Circle" which was described to be "norm-developing" by Kachru. Hong Kong, as part of China, was situated under the "Expanding Circle" which was said to be "norm-dependent". About a year before Hong Kong changed its sovereignty, a new colleague of the first author coming from the U.S. asked the first author after reading a book on common spoken errors in Hong Kong (Boyle \& Boyle, 1991) why some of those examples mentioned in the book were considered errors, but not features of a local variety. The fact is although a Hong Kong variety does exist with general public awareness in terms of a distinct accent (Bolton \& Kwok, 1990; Hung, 2000; Luk, 1998) and a body of new vocabularies (Macquarie dictionary, quoted in Bolton, 2000), it is not accepted as the variety to which Hong Kong English speakers aspire. Hong Kong English speakers, be they teachers or students, still look up to exonormative norms, that is, the norms provided by native-speaking countries, particularly Britain (e.g. Luk, 1998; Tsui and Bunton, 2000) for correct and acceptable models of pronunciation and usage. The interesting thing is this kind of mentality does not seem to be reflecting only linguicism or linguistic imperialism under the colonial rule, but seems to be becoming increasingly deep-seated and naturalized in the minds of most Hong Kong citizens after Hong Kong has ceased to be a British colony for more than five years. The following section reports some typical practices signifying a general tendency to move away from the WE paradigm in Hong Kong.

\section{Moving away from the WE paradigm? - Signifying practices in post-colonial Hong Kong}

The following evidence has been collected through the lived experience of the two authors over the last few years.

a) An ever-high deferential attitude towards the NETs ${ }^{i i}$ (Native English-speaking Teachers)

- A questionnaire survey on secondary students reveals that most students favoured the recruitment of NETs in schools because the NETs were felt to speak more 
"accurate" and "standard" English (Luk, 2001).

- In a lecturer-student consultative meeting at the Institute where the first author is a member, English major students who were all in-service English teachers commented negatively on the English accents used by some local lecturers teaching English and requested more expatriate lecturers. Similar student comments have also been received by several local colleagues and also colleagues from non-English-speaking places.

- At a focus group meeting organized by the Education and Manpower Bureau to develop Basic Competency Assessment tasks for primary pupils, a local English teacher pointed out the importance of clear and proper pronunciation in the audio-recordings of the materials which were done by local English teachers as trial materials for the pilot assessments. This point was immediately taken up by the chairperson and some other members as indicating the need to recruit native speakers to do the recording.

- After a programme-publicity talk organized by a teacher education Institute in a local secondary school, the school principal queried why the Institute did not send an expatriate lecturer to publicize their English major programmes. It has been brought to the notice of the Institute managerial level that the English Department had too few native English-speaking lecturers and this might have adversely affected the profile of the English Department.

- About a year ago, a Radio Hong Kong early morning infotainment programme began to air a 10-minute section on English idioms. At the beginning, the male host who in the authors' opinion speaks good English demonstrated the reading of the idioms. However, a few days later, a native speaker model was provided and the male host reiterated that this was the standard model and urged the public to follow the native speaker model. It is interesting to note that one native speaker model presented actually carried noticeable regional accents, but the host still presented it as the "norm" that all other co-hosts and the public should follow.

b) Media and public discourses on "proper" English pronunciation

- A campaign was launched jointly by the Hong Kong Education City and Oxford University Press to teach teachers and students IPA in order to enhance their awareness of the differences between Cantonese and English phonology. According to the consultant of the project who is a Chinese teaching comparative phonetics at the University of Hong Kong, "Cantonese speakers are particularly prone to accent-laden spoken English" because "more than 40 percent of the English phonetic sounds are different from the Cantonese ones" (South China Morning Post, 15 November 2003, italics added). This seems to imply that only Cantonese-accented English is a kind of accent, and the phonological features of Cantonese, by being so different from those of the English phonetic system, have created "obstacles" to speaking "better" English (as suggested by the name of their website www.speakbetterenglish.com.hk.). This might have given the public the impression 
that "good" English is spoken without an accent.

- A couple of local celebrities who are felt to be speaking "standard" British English (e.g. generally referring to RP) have recently been invited to appear in radio and TV programmes and write in newspaper columns to rectify common pronunciation errors in Hong Kong. One such celebrity is a retired barrister, Sir Tie Liang Yang, who received university education in the UK. The pronunciation errors he identified recently included pronouncing the silent " $h$ " in "Beckham", pronouncing the first syllable of "southern" in the same way as "south", and adding a schwa to the second syllable of 'couldn't' $/: \kappa Y \delta \leftrightarrow \nu \tau /$ (instead of using the syllabic /n/), etc. To the authors, some of these features reflect the lack of consistency in the sound-spelling relationship of English, and should be approached as problematic features of the English language rather than as careless errors made by Hong Kong people.

\section{c) Language proficiency assessments for English teachers}

The most powerful mechanism to bring about standardization of norms conforming to the BANA-centric models in Hong Kong is by far the Language Proficiency Assessment for Teachers (LPAT for short). The LPAT started to be enforced in 2001 to ensure that teachers of English and Putonghua all reach a publicly-recognized benchmark level in terms of language proficiency. Pronunciation is an assessment item for the read aloud task of the speaking test and the classroom language use. It was generally believed that only "native" speakers or speakers with "native-like" proficiency could attain level 5 which is the highest level in terms of pronunciation, stress and intonation because the descriptors at this level require pronunciation to be "completely error-free with no noticeable first language (L1) characteristics" (Government of Hong Kong Special Administrative Region, 2000, p.110). These descriptors again allude to a close connection between pronunciation errors and L1 characteristics, and also imply that error-free pronunciation is also accent-free.

Shohamy (2003) argues forcefully how powerful language tests can be in changing people's behaviour. The impact of LPAT tests on public attitude towards language proficiency has been tremendous. Glenwright (2002) reveals a growing tendency for Hong Kong school teachers to focus more than ever on accuracy in marking pupils' writing because one component in the LPAT writing tests requires candidates to identify and explain pupils' errors in compositions. This was found to be undermining pupils' creativity in writing. Similar self-disciplining has also been observed in the aspect of pronunciation.

Ms K (a pseudonym), a Cantonese-speaking local teacher educator who was by training a speech pathologist in the States, has been actively involved in concrete application of the criteria in actual assessments of LPAT candidates' pronunciation, stress and intonation. In one of the standardization meetings Ms K conducted for a group of potential assessors which the first author attended, Ms K classified as errors pronunciation features such as 
replacing $/ \Delta /$ with $/ \mathrm{d} /$ (e.g. "there" pronounced as "dare"); replacing the dark $/ \mathrm{l} / /$ with $/ \mathrm{u} /$ (e.g. "apple" pronounced as $/: \Theta \pi \leftrightarrow \mathrm{Y} /$ ) or dropping it altogether (e.g. "mall" pronounced as "more"); and placing equal stress on multisyllabic words (e.g. "autumn" pronounced as /: $7: \tau \wp \mu /)$. In an interview with the first author, Ms $\mathrm{K}$ asserted that although these features did not normally create intelligibility problems, any features that do not conform to the British RP or American GA accents would be considered problematic by her. However, she went on to clarify that her judgments excluded accent features of other native English varieties such as Australian, New Zealand, or Canadian accents. Ms K admitted that this was discriminative but inevitable because of the existence of LPAT. In her present job as a speech consultant at a teacher education institute in Hong Kong, she would advise local student teachers to try to reduce and/or eliminate any L1 characteristics because in her understanding, these L1 characteristics would disadvantage them in their LPAT assessments.

The Hong Kong case seems to be revealing a desire to diverge from the WE paradigm. It seems to be a strong case illuminating Phillipson's (1992) configuration of "English linguistic imperialism" and "linguicism" (which means the inequitable allocation of language rights, see Skutnabb-Kangas, 1998) in which people engage themselves in a "biased process of hierarchization of "legitimate and illegitimate offspring of English"" (Phillipson, 2000, p.88, quoting Mufwene, 1997) and the people who produce them. The question, however, is who are the agents effectuating the process of linguistic imperialism in post-colonial Hong Kong? Pennycook (2000) points out the importance of understanding the politics of global dominance of English through "contextual sociologies rather than a priori assumptions about imperialistic effects" (p.118). What sustains the local hegemony of English may largely be the local forces. In the next section, we will attempt to explain such local hegemony in Hong Kong by drawing on theory from post-colonial and sociocultural studies.

\section{Uncovering the sociopolitics in hegemonic privileging of BANA-centric accents in post-colonial Hong Kong}

While the domination of English in Hong Kong is a clear case of colonialism and linguistic imperialism, the perpetuation of the local hegemony of English, and in particular, English spoken with the BANA-centric linguistic norms, seems to be an ideology of local production. Hegemony, in Gramsci's (1971, p.28) sense, means "domination by consent":

Fundamentally, hegemony is the power of the ruling class to convince other classes that their interests are the interests of all. Domination is thus exerted not by force, nor even necessarily by active persuasion, but by a more subtle and inclusive power over the economy, and over state apparatuses such as education and the media, by which the ruling class's interest is presented as the common interest and thus comes to be taken for granted." (Ashcroft, Griffiths \& Tiffin, 2000, p.116) 
In this sense, the privileging of the BANA-centric pronunciation norms is a clear case of hegemony in Hong Kong. The radio programme, the proliferation of the NET Scheme, the LPAT assessment, and the "speakbetterEnglish" campaign are all examples of "state apparatuses" to construct and effectuate an accent-based linguistic hierarchization with Inner Circle norms being given privileged status while local features are suppressed to the lower end and presented as errors.

Some readers might feel puzzled about the emergence of this mentality as the change of sovereignty has been in effect since 1 July 1997 and the ruling class is no longer the colonial master from Great Britain. Why would the ruling class which is almost all composed of Hong Kong Chinese still want to subscribe to the hegemonic domination of the former colonizer's language and their linguistic norms? Why is Hong Kong unlike other post-colonial places such as India, Pakistan and Sri Lanka where citizens took pride in speaking the colonizers' language in their local manner?

A widely-acceptable explanation points to the utilitarian and practical minds of Hong Kong people. The Chief Executive of the Hong Kong Special Administrative Region, Tung Chee-wah, in his October 1999 Policy Address, highlighted his vision of Hong Kong as a "world-class city", explaining that "Hong Kong should not only be a major Chinese city, but could become the most cosmopolitan city in Asia, enjoying a status comparable to that of New York in North America and London in Europe" (Bolton, 2000, p.283). To be a cosmopolitan city, a high English standard is indispensable. Actually, the hegemonic status of English all over the world has often been fortified by the notion of "globalization." In the face of a globalized economy and the need to conduct transnational communication, the ability to speak English as an international language intelligibly is of crucial importance. Even in Singapore where local people prefer using local varieties in order to sound like Singaporeans but not like Englishmen, Standard English is still generally viewed to be superior and the "ideal" form of English to which highly educated people would aspire (Milroy \& Milroy, 1992). Therefore, having a good English standard is believed to be able to bring about personal social advancement. Li (2002), for example, after making a comprehensive review of Hong Kong's colonial history and language attitude development, argues that perpetuating the status and demand for English in the post-colonial period (as evident in the parents' strong preference for English-medium education) reveals a pragmatic self-pursuit of English as a "value-adding commodity" (p.50) rather than a passive acceptance of social control through linguistic imperialism. Therefore, when the mastery of the former colonizer's accent proves to be value-adding social and cultural capital (Bourdieu, 1991), many people would strive hard to attain the goal. For example, obtaining level 4 in LPAT would qualify the candidate to get promotion to the English panel chair position. A pragmatic self-pursuit of English seems to be a personal choice on the surface, but may indeed be a self-naturalized uncritical acceptance of linguistic control under the coercive force of state apparatuses. This seems exactly the kind of "domination by consent" Gramsci refers to. 
Apart from understanding the issue from Bourdieu's capital theory, we might be able to find some insights from a post-colonial mentality labeled as "post-colonial re-membering" (Gandhi, 1998). According to Gandhi (1998), post-colonial remembering denotes an ambivalent stage during which the colonized (i.e. the Orientals) tend to long for a certain form of continuity with the colonizers (e.g. U.S. and U.K.) who have often portrayed themselves as "the disinterested purveyor of cultural enlightenment and reform" (Gandhi, 1998, p.14), or, in Phillipson's (2000, p.98) words, "altruistic" in their foreign language policy. When the colonizers had left, people in the former colony may suffer a "stigma of unauthenticity" because "[t]he Europe they [i.e. the colonized] know and value so intimately is always elsewhere. Its reality is infinitely deferred, always withheld from them" (Gandhi, 1998, p.12). It must be pointed out that the majority of the ruling party in post-colonial Hong Kong were government officials holding crucial posts in the colonial government. Most of them had children studying overseas particularly Britain. These government officials who are still playing a part in devising Hong Kong's education and language policy may still be affectively attached to the former colonizer. This mentality might have been further reinforced by a mixed feeling of apprehension and untrust towards the Mainland China Communist ruling party particularly after the June 4 incident in 1989. It has been documented in works by local sociolinguists such as Chan (2002) and Lai (2003) that Hong Kong people before and after the 1997 sovereignty handover, particularly those born in Hong Kong, were very anxious to preserve and assert their Hong Kong identity. Accents, being powerful linguistic and identity markers, may have conveniently provided a form of social and cultural symbol for Hong Kong people to distinguish themselves from their fellow Mainlanders. Apart from speaking Cantonese with a "pure" Hong Kong accent, it seems that a Hong Kong identity also consists of the ability to speak English with a "standard" prestigious accent from the West.

\section{Deconstructing the BANA-centric hegemony of English in Hong Kong: Its likelihood of success}

From a sociopolitical perspective, as long as high-stake English proficiency assessment mechanisms such as TOFEL, IELTS, and LPAT continue to be in the control of the Anglo and US-centric hands, it is unlikely for World Englishes varieties to enjoy high status and wide acceptance as institutional varieties of English. To enable L2 English learners to score good grades in these tests so that they could have better advancements in their life opportunities, educationalists are often subject to demands that they should teach pupils to speak and write English "properly" by conforming to the "Standard" models.

From an applied linguistics perspective, the term "World Englishes" by its nature seems to be defeating its purpose to achieve globally intelligible communication by advocating "pluricentricity" (Clyne, 1992) of standards. As Jenkins (1998) argues, when local norms diverge too far from each other, international unintelligibility will be the result. Informal sharing with fellow local colleagues in Hong Kong by the authors reveal that we often 
had difficulties understanding English spoken with strong national accents such as Japanese or Korean at international conferences. We conjecture that if we speak with a strong Hong Kong accent, some Japanese or Koreans might find our speech unintelligible too. Therefore, who is to suffer with the continued promotion of World Englishes? It could be the World Englishes speakers themselves. By speaking English in their own ways, they may feel gratified by being able to assert their national identity. However, at the same time, they may also be diverging from the "points of reference and models for guidance" (Jenkins, 1998, p. 124) so far away that what they speak is beyond recognition by other World Englishes users.

Are we then suggesting that the WE paradigm should be forgotten and we should let Inner Circle varieties of English continue to enjoy their hegemony? Not really. By revealing representative signifying practices epitomizing not just the hegemonic privileging of English varieties spoken with Anglo and US-centric accents in post-colonial Hong Kong due to social and political considerations, the authors wish to make our voices heard by proposing three paradigmatic reforms in terms of assessment, research, and curriculum for the reflection of World Englishes users and activists.

\section{Towards three reform paradigms - assessment, research and curriculum}

In the assessment paradigm, the authors feel that there is a need to review the concepts of accents and errors in high-stake proficiency assessment mechanisms such as LPAT in Hong Kong. As rightly argued by Davidson (1993), "part of a test's standard is ...the linguistic norm it promotes", and that "[i]t would be detrimental to believe that the linguistic standard promoted by a language test is somehow divorced from other considerations of testing ethics", and therefore, it would be "unwise to develop and promote EFL tests without attention to the linguistic norms to which those tests adhere" (p.114). In the case of LPAT, the descriptors seem to imply that pronunciation free from L1-characteristics would be considered error-free. The general belief that only candidates with native speaker proficiency could attain the highest level for pronunciation, stress and intonation seems to be conveying the faulty view that native English speakers do not speak with an accent, and their linguistic features would be taken to be the norms for the standards of the test. This is problematic because it has been well-documented that Inner Circle native English speakers speak English with a range of variations (see Bauer, 2003). However, the situation with LPAT is although the "L1 characteristics" of some of these "native" English speakers may be noticeable, their "L1" characteristics would not be considered errors by assessors such as Miss K, and probably the chief examiners and the assessors the majority of whom are Inner Circle native English speakers who are relatively more familiar with most Inner Circle accents than those from the outer and expanding circles. It will therefore not be surprising that a native Australian who speaks English with noticeable Australian English accents would be likely to score higher that a native Chinese who speaks with noticeable Chinese accents even though both speak English with an accent. Taking into consideration how high-stake assessment exercises 
such as LPAT affect people's life chances, something needs to be done to counteract this "linguistic subordination" (Lippi-Green, 1997) and hegemonic practices.

However, we do understand that there is a need for any assessment mechanism to have an agreed standard. We acknowledge the need to distinguish between local accents and careless speech. Our contention is that if English is to enjoy the status of a world language, it should not be the sole privileges of the BANA-centric speakers to dictate the norms of usages for a more or less equal, or indeed growing, number of English L2 users $^{\mathrm{iii}}$ (Lowenberg, 2000). So there is an urgent need for test designers and assessors in ESL/EFL settings to set standards based on a widely accepted local educated speaker variety. Such a variety should have its linguistic base on a wider spectrum of educated professionals, not just a narrow circle of elitist language specialists. Reference could be made to representative literature (e.g. Bolton \& Kwok, 1990; Hung, 2000) reporting the existence of a local variety of Hong Kong English with systematic features of its own used by educated people (e.g. university students). However, as mentioned before, national/regional varieties that deviate too far away from the standardized Inner Circle models may result from mutual unintelligibility among their users. Therefore, world Englishes varieties would still need to undergo some sort of "standardization" process, though not necessarily converging to the BANA-centric norms, to ensure that they serve the purpose of facilitating international communication, and this leads us to the research paradigm.

\section{The research paradigm}

The adoption of the singular form "World English" by Brutt-Griffler (2002) seems a result of the realization that there needs to be some internationally acceptable norms for a World language. However, exactly what this "World English" entails in terms of phonology, syntax, lexis and pragmatics remains uncertain. Jenkin's (2000) work to establish a core set of phonological features for an international variety of English is a laudable attempt. However, the selection of features based on the criteria of frequency of occurrence and teachability-learnability might not fully reflect phonological features of native languages in the outer and expanding circles, and might not fully address pronunciation-based communication problems. An international language for communication across the world must take into consideration the linguistic features of different families of languages across the world. The establishment of the common denominator of the World English phonologies, for example, should be a world project which solicits the joint efforts of phonologists from a variety of ethnic backgrounds well-versed in the major English varieties and their own L1 phonological systems. To begin with, a common regional system could be established first. For example, there could be an Asian Pacific variety of World English pronunciation based on representative authentic speech samples from educated speakers from the composite varieties. Some form of corpora could be established from which mutual identifications of unintelligible phonological features could be identified from regional informants. For every target 
phonological feature, there would be a range of variants some of which will be incorporated as acceptable variants in the common regional variety after taking into consideration their systematicity in occurrence and degree of impact on cross-linguistic intelligibility.

The establishment of a regional variety of English with high mutual intelligibility does not aim to extinguish other forms of new Englishes suggested by Pennycook (2003) within a national boundary to cater for creativity and popular culture. However, we would like to see some sort of linguistic "role differentiation" (as against hierarchization) in the different forms of Englishes within a nation or a region. We believe that a truly multilingual person should have at his/her command a repertoire of varieties to suit different communicative contexts and purposes.

\section{The curriculum paradigm}

However, any attempt to establish non-BANA-based common regional varieties of English would be in vain if the World Englishes users are not aware of their existence, or are not motivated to accept their variants as codified and institutionalized models of usage (Brown, 2001). It has now been widely recognized that the achievement of common understanding in cross-ethnic and cross-cultural communication is the "mutual responsibility" and joint efforts of both interlocutors (Davis, 1991; Lippi-Green, 1997). As argued by Baxter (1991), Japanese English teachers could also speak English internationally if all speakers of English, including L1 speakers, could make an effort to cooperate to create an atmosphere of mutual acceptance. In this connection, we propose incorporating the more or less codified regional varieties of English into the English learning curriculum for all English users with the intention of conducting international communication in English. These users should include those native English-speaking teachers, TESOL consultants, language proficiency assessors, TESOL curriculum and materials designers from all sectors of the concentric circles. This curriculum paradigm would necessitate a kind of "reverse training" on the part of the Inner Circle native English speakers of the diversity of acceptable linguistic variants emerging from World Englishes. A WE curriculum should also consist of ideological critique against the entrenched and long-standing linguistic hegemony which naturalizes the status and privileges of speakers who happen to speak the accents of the colonial masters.

\section{Conclusion}

In this paper, we discuss how and why British-Australian-North American models of English accents continue to enjoy hegemonic status in post-colonial Hong Kong despite the call for a liberal acceptance of multiple standards under the World Englishes paradigm. We approach the issue from a sociopolitical perspective focusing on the connection between linguistic capital and social and cultural capital; and an applied linguistic perspective focusing on the need to establish international mutual intelligibility. To counteract an uncritical naturalization of the hegemonic ideology, we call for world 
efforts in reforming three paradigms, namely the assessment, the research, and the curriculum paradigms with a view to reviewing test standards in EFL settings, achieving common understanding of mutually intelligible regional varieties of English beyond national boundaries, and establishing World Englishes linguistic systems as core components in TESOL curriculum.

\section{References:}

Ashcroft, B., Griffiths, G. \& Tiffin, H. (2000). Post-Colonial Studies: The Key Concepts. London \& N.Y. : Routledge.

Bauer, L. (2003). An Introduction to International Varieties of English. Hong Kong: Hong Kong University Press.

Baxter, J. (1991). How should I speak English? American-ly, Japanese-ly, or internationally? In A. Brown (ed.). Teaching English pronunciations: A Book of Readings. London \& N.Y.: Routledge.

Bolton, K. (2000). The sociolinguistics of Hong Kong and the space for Hong Kong English. World Englishes, 19(3), 265-285.

Bolton, K. \& Kwok, H. (1990). The dynamics of the Hong Kong accent: Social identity and sociolinguistic description. Journal of Asian Pacific Communication, 1(1), 147-173.

Boyle, J. \& Boyle, L. (1991). Common Spoken English Errors in Hong Kong. Hong Kong: Longman.

Bourdieu, P. (1991). Language and Symbolic Power. Cambridge, MA: Harvard University Press.

Bresnahan, M.J., Ohashi, R., Nebashi, R., Liu, W.Y., \& Shearman, S.M. (2002). Attitude and affective response toward accented English. Language \& Communication, 22, 171-185.

Brown, K. (2001). World Englishes in TESOL programs: An infusion model of curricular innovation. In A. Burns \& C. Coffin (eds.). Analysing English in a Global Context: A Reader. London \& New York: Routledge.

Brutt-Griffler, J. (2002). World English: A Study of its Development. Clevedon: Multilingual Matters Ltd.

Canagarajah, A. S. (1999). Interrogating the "native speaker fallacy": non-linguistic roots, non-pedagogical results. In G. Braine (ed.), Non-Native Educators in English Language Teaching (pp. 77-92): Lawrence Erlbaum Associates, Publishers.

(2000). Negotiating ideologies through English: Strategies from periphery. In T. Ricento (ed.).

Chan, E. (2002). Beyong pedagogy: language and identity in post-colonial Hong Kong. British Journal of Sociology of Education, 23(2), 271-285.

Clyne, M. (1992). Pluricentric Languages: Differing Norms in Different Nations. Berlin: Mouton de Gruyter.

Crystal, D. (2003). English as a Global Language. Cambridge: Cambridge University Press. 
Davis, A. (1991). The Native Speaker in Applied Linguistics. Edinburgh: Edinburgh University Press.

Davidson, F. (1993). Testing English across cultures: summary and comments. World Englishes, 12(1), 113-125.

Eisenstein, M. (1983). Native reactions to non-native speech: a review of empirical research. Studies in Second Language Acquisition, 5(2), 160-176.

Gandhi, L. (1998). Postcolonial Theory: A Critical Introduction. New Delhi: Oxford University Press.

Glenwright, P. (2002). Language proficiency assessment for teachers: The effects of benchmarking on writing assessment in Hong Kong schools. Assessing Writing(8), 84-109.

Godfrey, P. (1993). Josiah's school drops English. Window, 2(19), 32-36.

Government of Hong Kong Special Administrative Region (2000). Syllabus Specifications for the Language Proficiency Assessment for Teachers (English Language). Hong Kong.

Gramsci, A. (1971). Selections from the Prison Notebooks of Antonio Gramsci. (Q. Hoare, \& N. Smith, Comps, \& Eds.). London: Lawrence and Wishart.

Harris, R. (1989). The worst English in the world. Inaugural lecture by the chair of English language. The University of Hong Kong.

Holliday, A. (1994). Appropriate Methodology and Social Context. Glasgow: Cambridge University Press

Hung, T.T.H. (2000). Towards a phonology of Hong Kong English. World Englishes, 19(3), 337-356.

Jenkins, J. (1998). Which pronunciation norms and models for English as an international language? ELT Journal, 52(2), 119-126.

(2000). The Phonology of English as an International Language. Oxford: Oxford University Press.

(2002). A sociolinguistically based, empirically researched pronunciation syllabus for English as an international language. Applied Linguistics, 23(1), 83-103.

(2003). World Englishes: A resource book for students. London \& New York: Routledge.

Kachru, B. (1986). The Alchemy of English: The Spread, Functions and Models of Non-native Englishes. Oxford: Pergamon Press, reprinted 1990, Urbana: University of Illinois Press.

(1992). Teaching World Englishes. In B. Kachru (ed.). The Other Tongue. English Across Cultures, $2^{\text {nd }}$ edn, Urbana, IL: University of Illinois Press.

(1996). The paradigms of marginality. World Englishes, 15(3), 241-255.

Lai, M.L. (2003). Cultural identity and language attitudes in postcolonial Hong Kong. Paper presented in the International Conference in Language, Education, and Identity (LED)

Lau, E. (1991). The future tense. Far Eastern Economic Review, 151(4), 18-19.

Li, D. (2002). Hong Kong parents' preference for English-medium education: passive victims of imperialism or active agents of pragmatism? In A. Kirkpatrick (Ed.), 
Englishes in Asia: Communication, Identity, Power \& Education (pp. 29-62). Australia: Language Australia.

Lippi-Green, R. (1997). English With An Accent: Language, Ideology, and Discrimination in the United States. London \& New York: Routledge.

Lowenberg, P.H. (2000). Non-native varieties and the sociopolitics of English proficiency assessment. In J.K. Hall and W.G. Eggington (eds.). The Sociopolitics of English. Clevedon: Multilingual Matters Ltd.

Luk, J.C.M. (1998). Hong Kong students' awareness of and reactions to accent differences. Multilingua, 17(1), 93-106.

(2001). Exploring the sociocultural implications of the Native English-speaker Teacher Scheme in Hong Kong through the eyes of the students. Asia-Pacific Journal of Language in Education, 4(2), 19-50.

McArther, T. (1987). The English languages. English Today, 11, 9-13.

(1993). The English language or the English languages? In W.F. Bolton and D. Crystal (eds.) The English Language. London: Penguin Books.

Milroy, J., \& Milroy, L. (1999). Authority in Language: Investigating Standard English: London \& N.Y. : Routledge.

Modiano, M. (1999). Standard English(es) and eductional practices for the world's lingua franca. English Today, 15(4), 3-13.

Mufwene, S. (1997). The legitimate and illegitimate offspring of English. In L.Smith \& M.L. Forman (eds.), World Englishes, (pp.182-203). Hawaii: University of Hawaii and East-West Center.

Parakrama, A. (1995). De-hegemonizing Language Standards: Learning From (Post)-colonial Englishes About 'Englishes'. Basignstoke, UIK.: MacMillan.

Pierson, H.D. (1998). Societal accommodation to English and Putonghua in Cantonese-speaking Hong Kong. In M.C. Pennington (ed.) Language in Hong Kong at Century's End. Hong Kong: Hong Kong University Press.

Pennycook, A. (1994). The Cultural Politics of English as an International Language. London and New York: Longman.

(2000). Language, ideology and hindsight: Lessons from colonial language policies. In T. Ricento (ed.).

(2003). Global Englishes, rip slyme, and performativity. Journal of Sociolinguistics, 7(4), 513-533.

Phillipson, R. (1992). Linguistic Imperialism: Oxford University Press.

(2000). English in the New World Order: Variations on a theme of linguistic imperialism and "World" English. In T. Ricento (ed.). Ideology, Politics and Language Policies: Focus on English. Amsterdam/Philadelphia: John Benjamins Publishing Company.

Purves, W. (1989). Statement to shareholders by W. Purves, Chairman, at the Annual General Meeting on 9 May 1989. Hong Kong: Hong Kong Bank.

Rampton, M. B. H. (1990). Displacing the 'native speaker': expertise, affiliation, and inheritance. ELT Journal, 44(2), 97-101.

Ricento, T. (ed.). Ideology, Politics and Language Policies: Focus on English. 
Amsterdam/Philadelphia: John Benjamins Publishing Company.

Selinker, L. (1992). Rediscovering Interlanguage. London: Longman.

Shohamy, E. (2003). The power of language tests in supressing language diversity in multilingual societies. Paper presented in the International Conference in Language, Education, and Identity (LED).

Skutnabb-Kangas, T. (1998). Human rights and language wrongs: A future for diversity? Language Sciences 20(1), 5-28.

Smith, L. (ed.) (1983). Readings in English as an International Language, Oxford: Pergamon Press.

South China Morning Post (15 November 2003). ELT site provides teacher support.

Surry, M. (1994). English not spoken here. Window, 3(12), 32-37.

Tsui, A.B.M. \& Bunton, D. (2000). The discourse and attitudes of English language teachers in Hong Kong. World Englishes, 19(3), 287-303.

Widdowson, H. G. (1993). The ownership of English. TESOL Quarterly, 28(2), 377-389.

\section{Notes:}

${ }^{\mathrm{i}}$ The global spread and use of English is conceptualized by Kachru (1992) as forming three concentric circles namely the Inner Circle, Outer Circle, and Expanding Circle. The Inner Circle comprises countries where English is spoken as a native language. The Outer Circle consists of mainly former colonies of Britain and U.S.A. where English is used as a second language, whereas the Expanding Circle refers to countries where English is learned as a foreign language.

ii In 1998, the first batch of more than 300 NETs was recruited to teach at secondary levels on a territory-wide basis. With the NETs, the government hopes that an authentic environment for using English will be created in local secondary schools, and the English standard of both the students and the local English teachers can be raised. Two years ago, the NET Scheme was extended to primary level schools.

iii According to Crystal (1997), the figure for L2 English speakers could amount to 350 million as compared to 340 million of L1 speakers. 